\title{
Taming of the Few - \\ The unequal distribution of greenhouse gas emissions from personal travel in the UK
}

\section{First and corresponding author}

Christian Brand, DPhil (Oxon) MSc Dipl.Phys.

Environmental Change Institute

Oxford University Centre for the Environment

South Parks Road

Oxford, OX1 3QY, UK

$\mathrm{T}:+44(0) 1865285177$

F: $+44(0) 1865275850$

christian.brand@ouce.ox.ac.uk

\section{Second author}

Brenda Boardman, $\mathrm{PhD}$

Environmental Change Institute

Oxford University Centre for the Environment

South Parks Road

Oxford, OX1 3QY, UK

$\mathrm{T}:+44(0) 1865285170$

F: +44 (0)1865 275850

brenda.boardman@eci.ox.ac.uk

Note: this is a personal version, created by Christian Brand, of the text of the accepted journal article. It reflects all changes made in the peer review process, but does not incorporate any minor modifications made at the proof stage. The complete citation for the final journal article is:

- Brand, C., Boardman, B., 2008. Taming of the few - The unequal distribution of greenhouse gas emissions from personal travel in the UK. Energy Policy 36, 224-238.

- $\quad$ DOI: http://dx.doi.org/10.1016/j.enpol.2007.08.016

Copyright (C) and Moral Rights for this paper are retained by the individual authors and/or other copyright owners 


\section{Abstract}

Greenhouse gas emissions from personal transport have risen steadily in the UK. Yet surprisingly little is known about who exactly is contributing to the problem and the extent to which different groups of the population will be affected by any policy responses. This paper describes an innovative methodology and evaluation tool for profiling annual greenhouse gas emissions from personal travel across all modes of travel. A case study application of the methodology involving a major survey of UK residents provides an improved understanding of the extent to which individual and household travel activity patterns, choice of transport mode, geographical location, socio-economic and other factors impact on greenhouse gas emissions. Air and car travel dominate overall emissions. Conversely, land based public transport accounts for a very small proportion of emissions on average. There is a highly unequal distribution of emissions amongst the population, independent of the mode of travel, location and unit of analysis. The top $10 \%$ of emitters are responsible for $43 \%$ of emissions and the bottom $10 \%$ for only $1 \%$. Income, economic activity, age, household structure and car availability significantly influence emissions levels. Key policy implications of the results are discussed. The paper concludes by suggesting potential applications of the methodology and evaluation tool.

\section{Acknowledgements}

This paper stems from research partly funded by the UK Economic and Social Research Council with additional funding from the Environmental Change Institute at Oxford University. The authors would like to thank Prof John Preston for his valuable comments on earlier drafts. The views expressed by this paper remain those of the authors and do not necessarily reflect those of the funders.

\section{Keywords}

Personal travel, travel behaviour, $\mathrm{CO}_{2}$, greenhouse gas emissions, energy policy, emissions distribution, socio-economic 


\section{Introduction}

\section{Research motivation and objectives}

In 2004, greenhouse gas (GHG) emissions from personal travel activity represented $18 \%$ of all UK domestic GHG emissions (DEFRA, 2006a). This share is significantly higher when international travel by air and shipping is included (Cairns and Newson, 2006). Travel by car and air make up the lion share of these emissions, with significant increases expected over the coming decades (DEFRA, 2006a). Yet surprisingly little is known about who is contributing to the problem, what the GHG profile of the population is and the extent to which different groups of the population will be affected by any responses to the problem. Research by, for example, Hillman and Walley (1983), Banister (1993), Hughes (1994), Greening (1997), Anable (1997), and more recently Greening (2004) identify that different subgroups in the population, described by various socio-economic, demographic and other personal characteristics, have different levels of emissions from personal motorised transportation.

The focus of national initiatives to mitigate climate change has so far been on vehicle technology fixes and economic instruments such as differential fuel/vehicle taxation and pricing road usage (IPPR, 2003). Many believe (e.g. Bristow et al., 2004, Hickman and Banister, 2006) that the UK government's recent commitment to a $60 \%$ cut in carbon dioxide $\left(\mathrm{CO}_{2}\right)$ emissions between 1990 and 2050 as set out in the Energy White Paper (DTI, 2003) is unlikely to be achieved by technology fixes and market-based measures alone. A whole raft of measures are likely to be required to meet this goal, in particular with regards to including private vehicle use and international aviation. As the world community is facing tough choices as how to respond to climate change, it is crucial to know who is contributing to the problem and to what extent will different groups of the population be affected by those choices. Part of this debate is hampered by the apparent lack of information on the GHG distribution within the transport sector, in particular with regards to annual travel activity and international travel at the personal level. This lack of appropriate data makes policy development difficult. Most national work on UK transport energy use (e.g. Stead, 1999, Banister and Banister, 1995) is based on travel activity data from the National Travel Survey (NTS) (ONS, 2005) and emissions factors from national sources such as the National Atmospheric Emissions Inventory (currently under review, with the most recent inventory reported in NETCEN, 2003). However, the NTS collects disaggregate data per household or individual in a weekly timeframe only. There are also limitations as to what long-distance trips (defined in the NTS as 
trips of 80 kilometres or more) are included. In the NTS, respondents are asked to record some details of long-distance trips for an extra three week period preceding the travel week only, thus missing the majority of the preceding year (ONS, 2005: p.22). Crucially, the NTS only includes trips within Great Britain, thus excluding international travel which, as presented later, can have huge impacts on GHG emissions production. From this it is clear that the NTS is unlikely to be an appropriate source of data for disaggregate profiling of annual emissions across all passenger transport modes. A new data collection method was needed.

The goal of the research summarised in this paper was to develop and test an innovative methodology for profiling climate change emissions from personal travel at the local, household and individual levels and to use this information to develop measurement, information and forecasting tools for use in (a) the assessment and monitoring of transport strategies and policies, (b) awareness raising, feedback and advice to households and individuals and (c) aggregate emissions forecasting. To achieve this aim, this research had the following working objectives:

- To extend previous work on travel emissions profiles (Anable et al., 1997) to include public transport, air travel, motorcycling, walking and cycling in a broader geographical setting;

- To develop a detailed evaluation 'tool' of GHG emissions at the household and individual levels;

- To collect, via conventional paper-and-pen based and web-based surveys, detailed disaggregate data as a basis for travel emissions auditing at the household and individual levels;

- To validate the evaluation 'tool' using the data collected in the surveys;

- To assess policy implications for local and national governments.

GHG emissions are expressed as mass of carbon dioxide equivalent $\left(\mathrm{CO}_{2}{ }^{\mathrm{eq}}\right)$, a metric measure used to compare the emissions from various GHGs based upon their 100-year Global Warming Potential (GWP) (Houghton et al., 2001), with respective 100-year GWP of 23 and 296 for $\mathrm{CH}_{4}$ and $\mathrm{N}_{2} \mathrm{O}$ expressed in terms of $\mathrm{CO}_{2}$. The one exception is air travel, where GWP can not be used and no comparative metric currently exists (Wit et al., 2005, Shine et al., 2005). To make a more general assessment of relative emissions impacts, this research applies the Precautionary Principle (UNCED, 1992) in using an alternative 'weighting' coined the Aviation Impacts Multiplier (AIM), with values based on the most upto-date figures for the Global Temperature Potential metric (between 1.5 and 3, with central value of 2, according to Wit et al., 2005) and the most reliable estimations of the Radiative Forcing metric by the 
IPCC (Penner et al., 1999) and more recently the TRADEOFF project (Sausen, 2005). For the purposes of this research, the new multiplier is represented by low (1.5), central (3) and high (4) values.

\section{This paper}

The paper will begin by briefly reviewing the background to personal travel and its relevance to climate change. Secondly, the methodology used to collect disaggregate travel behaviour and emissions data on a sample population of UK residents is outlined, as is the use of a newly developed GHG emissions evaluation tool to derive integrated travel emissions profiles. Thirdly, the individual, household and areawide emissions profiles are analysed and examined as to how geographical location, socio-demographic factors and other personal characteristics influence emissions levels. The implications for those responsible for the design of greenhouse gas emissions reduction policies are discussed. Finally, the potential applications of the methodology and tool are outlined.

\section{Personal Travel and Climate Change}

The UK Department for Transport ascribes the huge growth in personal travel to a number of factors including increasing car ownership, falling real costs of motoring, falling car occupancy levels and increasing average trip lengths, based on empirical evidence collected in the NTS (ONS, 2005). Household car availability has continued to rise in Great Britain, with $74 \%$ of households having access to a car in 2004 , compared with $62 \%$ and $72 \%$ in $1985 / 86$ and $1998 / 2000$ respectively (ibid). Income is a factor relating to the number of trips and distance travelled. In 2004, people in the highest income quintile did $28 \%$ more trips than those in the lowest income quintile and travelled nearly three times further (ONS, 2005). In particular, those in the highest income group did twice as many trips and travelled over three times further by car than those in the lowest income quintile group. Rail use is much higher in the highest income quintile, partly because commuters to London in the highest income band account for a considerable proportion of rail travel. In particular, people on low incomes walk more than the national average and walking is more common in urban areas (The Pedestrians Association, 2001). Air travel has been less researched although the majority of the evidence suggests that there is a significant link between income and the demand for air travel (e.g. Brons et al., 2002; Cairns and Newson, 2006; Korbetis et al., 2006).

Travel patterns vary according to demographics, socio-economic aspects (e.g. gender, income, age, economic activity), ethnicity and culture (e.g. Banister and Banister, 1995, Carlsson-Kanyama and Linden, 
1999, Stead, 1999, Cameron et al., 2003, Best and Lanzendorf, 2005). However, when accounting for the dominant factors, evidence by e.g. Timmermans et al. (2003) has shown that household location does not add significantly to explaining the variation in travel patterns amongst the population.

Travel patterns and behaviour also vary according to environmental consciousness, energy costs (Fox, 1995, Nilsson and Kuller, 2000) as well as chosen lifestyles, personal preferences, worldviews and attitudes (Anable, 2005). Anable argues that classifications used to segment populations based on demographic variables or simple behavioural measures commonly used in transport research “may oversimplify the structure of the market" (ibid). The research described in this paper addresses some of these issues and contributes to the debate on what factors influence personal travel activity.

\section{Research Methodology}

\section{Overall Approach}

The research was based around a major survey of the population of Oxfordshire, a County located just West of London in the South East of England, using a number of survey techniques, to measure, evaluate and analyse GHG emissions from personal travel activity. The empirical research methodology employs three stages of data collection, preparation and analysis. First, an innovative household survey technique based on weekly and annual estimates of day-to-day and casual travel activity were used to collect the data required to measure the key determinants of greenhouse gas emissions from travel over a 12-month period. The survey was designed and developed in two formats: a postal paper-and-pen survey as well as a web-based survey. A multi-method approach was used to validate internally and improve accuracy of the final outputs. This was further augmented by secondary data from national and local sources. Secondly, an evaluation and calculation tool was developed in a series of inter-linked spreadsheets and databases. This was designed to incorporate travel activity data with emission rates for each GHG pollutant for a range of transport modes, vehicle characteristics, travel characteristics, times of day and operating conditions. Secondary data were collected for this stage on local emissions factors, fuel lifecycle emissions, public transport vehicle fleet and passenger loadings. Thirdly, the travel activity data were translated into emissions profiles, analysed at the individual and household levels and aggregated to higher levels. This included validation in terms of comparison with more aggregate datasets and national statistics. 


\section{Survey Design and Administration}

\section{Design and sampling}

The survey built on previous work (in particular Anable et al., 1997, Brög et al., 2004) and was designed to collect information from three study groups: the household, the individual and (if applicable) the driver of a car or motorcycle. Within each of the study groups, examination was made of how household location, structure, income, occupation, age, gender, vehicle ownership and choice of transport mode may affect travel emissions.

Two versions of the survey questionnaire were developed, piloted and then employed on a larger scale: a postal paper-and-pen version and a web-based version. The mailed out paper-and-pen questionnaire included a Household Form, a maximum of five Person Forms and five Vehicle Forms. The Household Form mainly requested details of the socio-economic background of the household members. It also collected simple accessibility data by asking respondents how long it takes them to access key services and opportunities such as employment, primary and secondary schools, further and higher education, local stores, larger supermarkets, shopping and commercial centres, sports and leisure facilities, railway stations and local bus stops. For local bus stops, weekday, Saturday and Sunday bus frequencies were also requested. The Person Forms requested details on regular daily/weekly travel and irregular travel by nonprivate transport modes over a period of 12 months during 2004/05. The Vehicle Forms collected vehiclespecific data (such as fuel type and recorded, estimated or guessed annual distance travelled) as well as vehicle use data for each driver in the household. Respondents were asked to give details on all private travel activity (distance travelled, duration, trips) over a period of 12 months. Table 1 gives an overview of the primary data collected in the surveys. The web-based version can still be accessed at www.tsu.ox.ac.uk/research/oxontravel (guest login: oxontravel, password: onthemove).

Table 1: Overview of primary survey variables

\begin{tabular}{l|l}
\hline Household and individuals & $\begin{array}{l}\text { Cycling, walking, bus, taxi, rail, ferry } \\
\text { - HH size and structure, personal incomes, occupation, age, } \\
\text { gender, vehicle availability and ownership }\end{array}$ \\
$\begin{array}{l}\text { - Access to key services incl. public transport } \\
\text { - Casual travel (e.g. holidays, visiting friends) }\end{array}$ \\
\hline Air travel & $\begin{array}{l}\text { Private vehicle information } \\
\text { - Flight origin, destination, stopovers }\end{array}$ \\
- Flight duration & - Make, model, age, fuel type, engine size \\
- Aircraft occupancy & - Total vehicle-kilometres by road type, trip distance \\
& - Shared use of vehicle within household \\
\hline
\end{tabular}




\section{Administration and responses}

The postal, pen-and-paper questionnaires were sent out to 900 randomly selected, non-commercial and private addresses in Oxfordshire. To stimulate higher response rates, it was administered with pre-paid return envelopes and a prize draw. Reminder procedures were used to chase non-respondents after two weeks of the initial mail-out. Overall, the postal survey was administered and the responses chased and collected over an 18-week period in early to mid 2005. For the web-based survey, a total of 532 emails were sent to individuals inviting them to participate in the survey. The sampling frame was based on email addresses on mailing lists provided by departmental administrators, including university members living in Oxfordshire.

\section{Emissions evaluation}

The GHG emissions evaluation tool uses a number of techniques and data sources. For travel by private motorised travel and air travel, the survey questionnaires collect data to a high level of detail. For car travel, the tool employs four alternative techniques to derive GHG emissions (Table 2). Car method A, for example, calculates emissions from equations relating pollutant emissions to fuel type, engine size, age, trip lengths and average speeds based on the set of speed-emission equations developed by the Transport Research Laboratory (Barlow et al., 2001) and others. Excess emissions from cold starts are also included (taking into account the shares of urban vs. non-urban driving) as are fuel life-cycle emissions based on the most recent work by CONCAWE (2006).

Table 2: The four alternative methods for calculating emissions from car travel

\begin{tabular}{|c|c|c|c|c|}
\hline & Method & Description & Main relationship & Main disaggregation \\
\hline$A$ & $\begin{array}{l}\text { Transport activity } \\
\text { and disaggregate } \\
\text { average emissions } \\
\text { factors } \\
\text { (reference method) }\end{array}$ & $\begin{array}{l}\text { Based on travel activity data } \\
\text { collected in the surveys and } \\
\text { emissions factors } \\
\text { disaggregated by fuel type, } \\
\text { engine size, Euro band and } \\
\text { average speed. }\end{array}$ & $\begin{array}{l}\text { emissions }=\text { emissions } \\
\text { factor } x \text { transport activity } \\
\text { (km, hours) } \\
\text { (Cars: plus excess } \\
\text { emissions from cold starts) }\end{array}$ & $\begin{array}{l}2 \text { propulsion technologies } \\
3 \text { fuel types } \\
3 \text { engine sizes } \\
6 \text { Euro standards } \\
3 \text { road types/speeds } \\
\text { (Cars: } 3 \text { trip lengths) }\end{array}$ \\
\hline$B$ & $\begin{array}{l}\text { Transport activity } \\
\text { and 'official' vehicle } \\
\text { specific emissions } \\
\text { factors }\end{array}$ & $\begin{array}{l}\text { Based on travel activity data } \\
\text { collected in the surveys } \\
\text { matched with vehicle specific } \\
\text { fuel use and emissions data } \\
\text { for each make, model, fuel } \\
\text { type and engine size }\end{array}$ & $\begin{array}{l}\text { emissions = f(car make, } \\
\text { model, fuel, engine size, } \\
\text { first year of registration) } \\
\text { taking figures from 'official' } \\
\text { databases, depending on } \\
\text { first year of registration }\end{array}$ & $\begin{array}{l}1000 \text { 's of combinations of } \\
\text { vehicle make \& model, fuel } \\
\text { type, engine size and first } \\
\text { year of registration } \\
2 \text { road types (urban/extra- } \\
\text { urban) }\end{array}$ \\
\hline $\mathrm{C}$ & Fuel consumption & $\begin{array}{l}\text { Direct conversion of fuel use } \\
\text { to emissions via carbon } \\
\text { balance }\end{array}$ & $\begin{array}{l}\text { emissions }=f(f u e l \\
\text { consumption and type) } \\
\text { (carbon balance) }\end{array}$ & $\begin{array}{l}3 \text { fuel types: petrol, diesel, } \\
\text { 'other' (LPG, etc.) }\end{array}$ \\
\hline $\mathrm{D}$ & Fuel expenditure & $\begin{array}{l}\text { Direct conversion of fuel } \\
\text { purchase and fuel type to fuel } \\
\text { use and emissions via } \\
\text { carbon balance }\end{array}$ & $\begin{array}{l}\text { emissions }=f(f u e l \\
\text { expenditure, price and type) } \\
\text { (carbon balance) }\end{array}$ & $\begin{array}{l}3 \text { fuel types: petrol, diesel, } \\
\text { 'other' (LPG, etc.) }\end{array}$ \\
\hline
\end{tabular}


The main method for bus, rail, taxi and ferry travel was based on transport activity (split into day-to-day and casual travel, with an indication of peak or off-peak travel), vehicle emissions factors and passenger loadings per vehicle. Two alternative techniques and sources of data were used to compare national and local averages based on differences in emissions factors and occupancy rates.

For air travel, three alternative techniques are used, all newly developed and based on the travel activity approach (one on trip distance, one on stated trip duration and one on calculated trip duration). Total annual emissions are derived using a two-step approach. First, top level travel activity indicators (passenger-kilometres, time spent in the air) are derived from data collected in the surveys for each flight (both directions, including stopovers). Secondly, the travel indicators are multiplied by emissions factors based on distance-emissions curves developed in this research. These distance-emissions curves were derived from market-share average-weighted fuel consumptions of seven of the most common aircraft types obtained from EEA (2005), which were further split into two distance classes (short-haul and longhaul, i.e. below or above 3,500 km flight distance). As the total distance includes all legs of a journey (single or return-out and return-back), so do the emissions totals include all legs, independent of where the aircraft was refuelled. In addition, the methodology takes account of the most important factors influencing fuel consumption, including the number of take-offs per trip, average passenger loadings, cargo factors, detours and holding patterns obtained from a number of sources (e.g. DLR, 2000, AEA, 2002, CAA, 2006). Further details can be obtained in Brand (2006).

\section{Results}

\section{The survey sample}

The paper-and-pen survey achieved a response of 171 out of 900 completed household returns (19\%), providing 339 individual travel profiles. In addition, the web-based survey achieved a response of 117 out of 532 completed individual returns (22\%). This provided a total sample size of 456 individuals living at 278 addresses. The sample showed large disparities between individuals: $72 \%$ of individuals held a driving licence, 59\% drove cars and/or motorcycles, 59\% made at least one flight over the year, $69 \%$ had used buses or coaches, $46 \%$ taxis, $52 \%$ rail and $15 \%$ ferry. Some $20 \%$ of respondents drove but didn't fly, while incidentally the same number (but not necessarily the same sub-sample) of respondents didn't drive but flew at least once. $39 \%$ did both, $21 \%$ did neither. 
The comparison of the socio-economic composition of the sample with UK Census data (ONS, 2001) showed that the sample was representative of the County population in terms of age structure, gender and economic activity (i.e. working status disaggregated by nine activity classes such as 'in full-time work', 'retired', 'at school', 'at university' and 'looking for work'). Despite the high degree of accuracy of representation, the results were corrected for response bias by gender, age and economic activity. Some caution with regard to the lower car ownership levels of the sample as compared to the County as a whole may have to be exercised.

\section{Validation and key methodological issues}

The integrity of the data collected was assessed as part of the validation exercise. Whilst the validation procedures have been unable to assess conclusively the accuracy of the data in so far as it is a true reflection of individual emissions from travel activity, the following conclusions can be drawn. As the survey used separate forms pertaining to each vehicle used in the household, supplemented by separate forms for each individual to break down their journey profiles, there was no clear indication of any double counting effects amongst drivers of cars or motorcycles when two people drove the same vehicle. However, the danger remains of creating an overly complex and time-consuming exercise which runs counter to the overall objective of designing an efficient and cost-effective survey to be carried out annually without detailed instruction.

The use of any documented evidence to record distance travelled, and any other pieces of information requested, produces considerably better results. Also, by asking respondents how accurate their estimates of the distance travelled by car or motorcycle are, an assessment of confidence levels was performed, thus keeping uncertainty to a minimum.

By investigating the multi-method approach used for car and air travel, the following can be concluded. First, methods A (based on travel activity and disaggregate emissions factors, see Table 2) and B (based on 'official' vehicle-specific fuel consumption and emissions figures) for car travel produced remarkably similar results overall. However, emissions varied considerably on a case by case basis, revealing how different approaches can lead to different results at the disaggregate level. Given the uncertainty in individual emissions totals, however, both methods produce largely similar results. Method A, however, is more disaggregate and leaves room for patterns to emerge relating to disproportionate usage of 
different road types and trip lengths. The emissions factor database for method A is also more complete and is used by local authorities in the UK for air quality management and planning. Method B provides one distinct advantage in that vehicle-specific emissions factors are used, as opposed to the more general emissions categories (by fuel type, engine size and vehicle age) used in method A.

For air travel, overall distance and duration estimates between the three tested methods E (distance based), F (based on stated duration) and $\mathrm{G}$ (based on calculated duration) can, at least at the sample level, be used interchangeably as the key parameters determining emissions from air travel.

Further aggregation of the results to national levels (England, UK) and comparison with national statistics provided a good match at the aggregate level (emissions and kilometres travelled, by mode), thus giving confidence in the integrity and relevance of the conclusions drawn at the aggregate levels.

\section{Area-wide travel emissions profiles}

The achieved sample size of 456 individuals allowed for a distinction to be made between a number of geographical area types without sacrificing sound statistical analysis of the sub-samples. Four geographical area types based on built-up/non-built area and population size were defined for the analysis, including large urban (built-up, population 100-250k, e.g. Oxford City), medium urban (built-up, population 25-100k), small urban (built-up, population 10-25k) and rural (non built-up, population <10k) areas.

\section{Travel activity}

Overall, travel by air and car dominates total distance travelled, accounting for $77 \%$ of total annual kilometres (Table 3). For air travel, the flying individuals (59\% of the sample) averaged about 17,400 kilometres, 24 hours in the air and 5.4 landing and take-offs (LTO) per person p.a. When looking solely at location, i.e. ignoring personal characteristics such as age and income, respondents living in medium and large urban areas travelled less by car and air (73\%) than respondents living in small and rural areas (87\%). Specifically, the distances travelled by car by residents living in large urban areas were $27 \%$ lower than the sample average while residents in rural areas travelled on average $46 \%$ further than the sample average. Conversely, residents living in large urban areas travelled $31 \%$ further by air than the sample average, whereas the distances travelled by air of residents living in small urban and rural areas were $23 \%$ and $30 \%$ lower than the sample average. For respondents living in large and medium urban areas, travel 
by public transport (rail, bus, coach, taxi) was significantly higher than the national average, reflecting the location of Oxford City and its surrounding urban centres in London's commuter belt and, for UK standards, the good provision of public transport services in central Oxfordshire.

Table 3: Total and average distance travelled by mode of transport and geographical area

\begin{tabular}{|c|c|c|c|c|c|c|c|c|c|c|}
\hline \multirow[b]{2}{*}{ Mode $\rightarrow$} & \multicolumn{10}{|c|}{ Distance travelled ${ }^{1}$ (passenger-kilometres) } \\
\hline & $\mathrm{Car}^{2}$ & $\begin{array}{l}\text { Motor- } \\
\text { cycles }\end{array}$ & Bus $^{3}$ & Cycle & Walk & Rail & Taxi & Ferry & $\operatorname{Air}^{4}$ & Total \\
\hline Survey total ('000) & 2,759 & 51 & 660 & 274 & 175 & 959 & 34 & 27 & 4,674 & 9,611 \\
\hline Person average & 6,050 & 113 & 1,448 & 599 & 385 & 2,101 & 74 & 60 & 10,249 & 21,076 \\
\hline - Large urban & 4,393 & 10 & 2,275 & 1,046 & 510 & 2,858 & 84 & 63 & 13,403 & 24,643 \\
\hline - Medium urban & 5,948 & 265 & 859 & 175 & 325 & 3,171 & 97 & 72 & 8,862 & 19,776 \\
\hline - Small urban & 6,534 & 60 & 819 & 261 & 237 & 681 & 24 & 6 & 7,863 & 16,483 \\
\hline - Rural & 8,747 & 201 & 822 & 341 & 294 & 764 & 64 & 74 & 7,202 & 18,510 \\
\hline National average & 5,582 & 55 & 533 & 58 & 315 & 698 & 79 & 51 & 5,871 & 13,242 \\
\hline
\end{tabular}

Notes: (1) The averages are per total sample or population, i.e. not averages of those in the sample that drove/flew/cycled/etc. Miles were converted to kilometres using a conversion factor of 1.609 kilometres per mile. ${ }^{(2)}$ Car as driver only, using method $A .{ }^{(3)}$ Includes local bus, express coach and community/minibus. ${ }^{(4)}$ Individual averages across the sample population, using method $E$.

Sources for comparison with national averages: ONS (2005); DfT (2005)

The above Table also provides a comparison of the average distance travelled per person with national statistics (DfT, 2005; ONS, 2005). This suggests that the travel activity figures compare well overall, in particular for travelling by car (as driver), taxi and walking. The sample averages for rail, local bus and cycling are clearly higher than the NTS figures. This can be explained by differences in the samples and methodology, e.g. the survey sample included trips by international high speed rail (e.g. Eurostar) whereas the NTS figures exclude non-domestic trips. Also, much of Oxfordshire lies within commuting distance to London, with very good rail and coach connections. Some respondents could be identified as Oxfordshire-London and Oxfordshire-Birmingham commuters, thus raising the average distance travelled by coach or train. The modal share of cycling in Oxford City (11\% in inner cordon) is also well above the national/regional average (2\%) (Oxfordshire County Council, 2000). In addition, the national average distance travelled by air was estimated from International Passenger Survey (IPS: ONS, 2005b) data for 2004 by first calculating the average trip length of a return trip for the IPS sample (4,895 miles), then multiplying the result by the total number of non-business visits abroad by UK residents (43.8 million), and finally dividing by the total UK population (58.8 million). The direct comparison between this 'topdown' figure and the 'bottom-up' figure derived in this study shows a modest difference, which may be explained by the difference in methodologies (the IPS only includes the first two legs of an air trip, while this study includes all legs), the higher share of (international) students in the sample, higher than average 
incomes and economic activity of Oxfordshire residents and the proximity of Oxford(shire) to four major international airports, providing better than average accessibility to leisure destinations.

\section{Travel emissions}

This travel activity translated into total GHG emissions of 5.2 tonnes of $\mathrm{CO}_{2}$ equivalent $\left(\mathrm{tCO}_{2}{ }^{\text {eq,tot }}\right)$ per person per year (all modes, method A for car, method $\mathrm{E}$ for air, central AIM value of 3). Figure 1 provides the modal breakdown of this total (central AIM value), suggesting that private travel by air $(70.2 \%)$ and car $(25.5 \%)$ dominate GHG emissions from personal travel activity. After accounting for the different approaches, this largely confirms results of other research and national statistics, namely that of Hillman and Fawcett (2004), ONS (2004) and DfT (2006). Emissions from air travel are the exception, where averages per person were significantly higher than e.g. in the ONS (2004) study. The variations can be explained by a combination of differences in accounting methods (e.g. this research accounts for both directions of a return flight, detours from the 'as-the-crow-flies' route, taxiing, cargo factor), emissions data sources and methods, local vs. regional variations (higher share in the sample of younger residents living in Oxford, e.g. a higher share of 19-35 old overseas students who tend to fly significantly more than the average person, as demonstrated later), and better than average access by car and public transport to major international airports.

Figure 1: Average $\mathrm{CO}_{2}{ }^{\text {eq,tot }}$ emissions per person by mode of transport $(A I M=3$, central value)

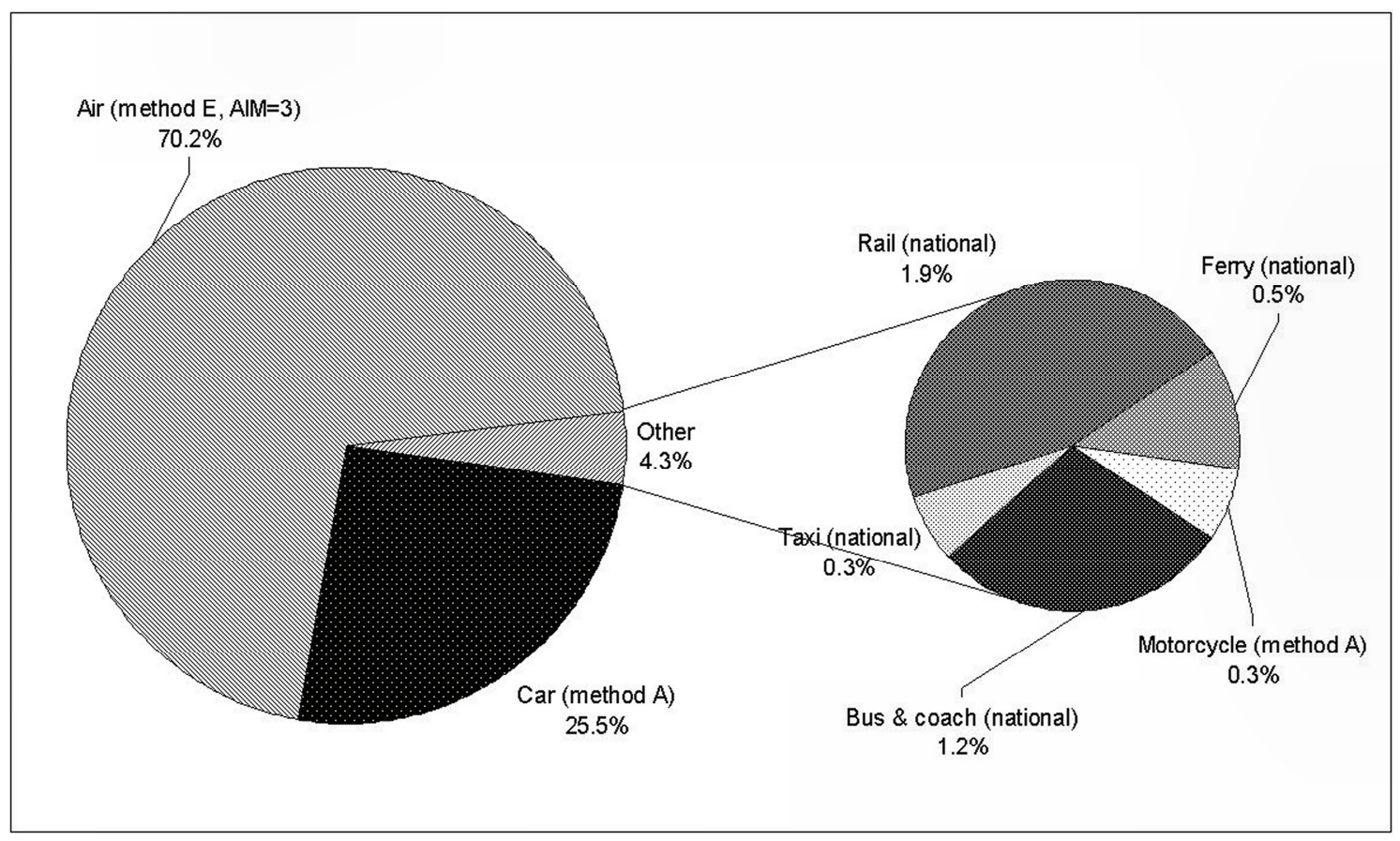

Base: all 456 individual responses. Note: 'national' depicts national average emissions and load factors. 
Again, when ignoring other factors influencing travel patterns such as income and age, GHG emissions varied considerably by geographical area, providing some important findings. First, average emissions from residents living in large urban areas (Oxford City) were 16\% higher than the sample average, whereas emissions were lower (between $-10 \%$ and $-18 \%$ ) for other areas. In particular, emissions from air, bus/coach, rail and taxi travel were disproportionally higher for residents in large urban areas than the sample average, while conversely they were responsible for $26 \%$ lower emissions from car travel. This can be explained by a combination of good accessibility to public transport and airports as well as the effects of local transport policy, which largely restricts access to the city centre for private car (but not taxi) travel. Interestingly, residents in rural areas are responsible for $41 \%$ higher than average emissions from car but $29 \%$ lower than average emissions from air travel.

Secondly, the $3.5 \%$ (central AIM value) share of the total from land-based public transport (bus, coach, minibus, rail and taxi) suggests that these modes can be considered insignificant overall. Even when ignoring non- $\mathrm{CO}_{2}$ effects of aviation (i.e. $A I M=1$ ), the share of the total of these modes is only $6.1 \%$. Although demonstrating the highest GHG emissions rates per passenger-km, average emissions from travel by passenger ferry (mainly Ro-Ro ferry links between the UK and mainland Europe) are below 1\% independent of the value for the AIM factor.

Respondents were further ranked in a continuous distribution (smallest first, i.e. rank 1 for lowest emitter) according to GHG emissions levels. For emissions from all travel, Figure 2 shows a highly unequal distribution between individuals. This suggests that a large proportion of the population produce similar travel and $\mathrm{CO}_{2}$ emissions profiles, whilst a few are responsible for a disproportionately large share of the total. In further analysis, the shape of the emissions ranking curve was found to be remarkably similar regardless of the area type, mode of travel or unit of analysis (individual, household, driver). 
Figure 2: Individual GHG emissions from all travel activity by area type, ranked by emissions totals

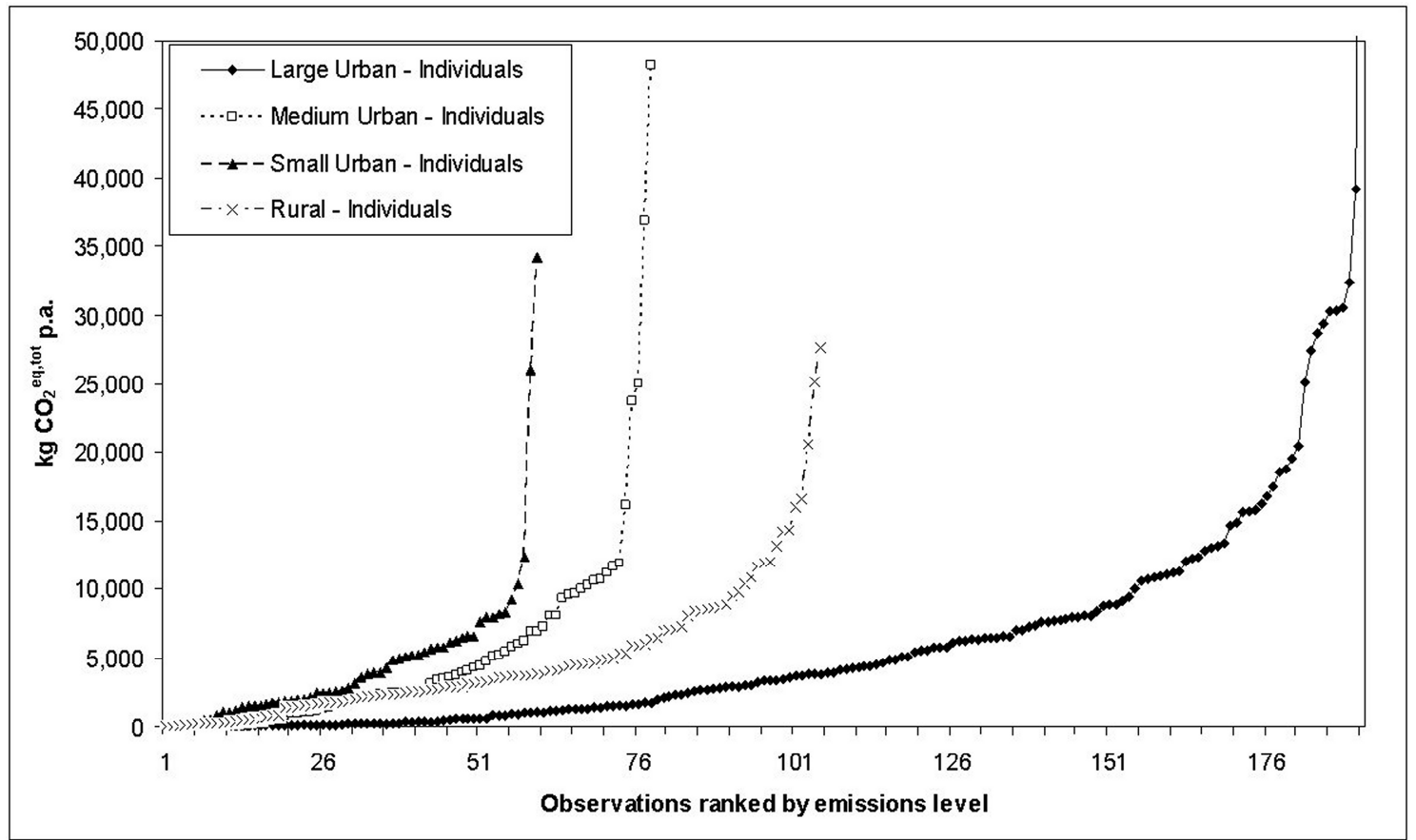

Base: 434 respondents who produced any emissions at all (i.e. excluding 22 non-emitters). Note: an 'outlier' of a respondent in large urban areas $\left(>90,000 \mathrm{tCO}_{2}^{\text {eq,tot }}\right.$ p.a.) is not shown.

\section{Travel emissions profiles by socio-demographic and other personal characteristics}

When the analysis of emission profiles moves from the area level to individuals and households, the scale of the disparities in travel and emissions becomes even clearer. In addition to the continuous distribution of emissions, the results were reduced so as to rank each individual or household according to where they lie in a scale of 'high' or 'low' emitters. Emissions were ranked and grouped into emissions quintiles and deciles, that is, into groups of a fifth and a tenth of the total case base each.

Overall, it is a minority of users, travelling comparatively long distances, who account for the differences between high and low quintiles. $61 \%$ of emissions were produced from respondents in the highest emissions quintile (20\%), but only less than $1 \%$ of emissions were generated from respondents in the lowest emissions quintile, implying a 'high-over-low' factor of 90 (Figure 3). The corresponding average GHG emissions from all travel activity were $16.6 \mathrm{tCO}_{2}{ }^{\text {eq,tot }}$ per person p.a. in the highest quintile, and 0.19 $\mathrm{tCO}_{2}{ }^{\text {eq,tot }}$ per person p.a. in the lowest quintile. When including only respondents who produced emissions from travelling by the mode under consideration, respondents in each highest emissions quintile accounted for between $47 \%$ (car) and $74 \%$ (taxi) of emissions, with a range of 'high-over-low' factors between 15 (car) and 70 (rail). 
Figure 3: Shares of total greenhouse gas emissions in each emissions quintile from 'low' to 'high' by mode of travel

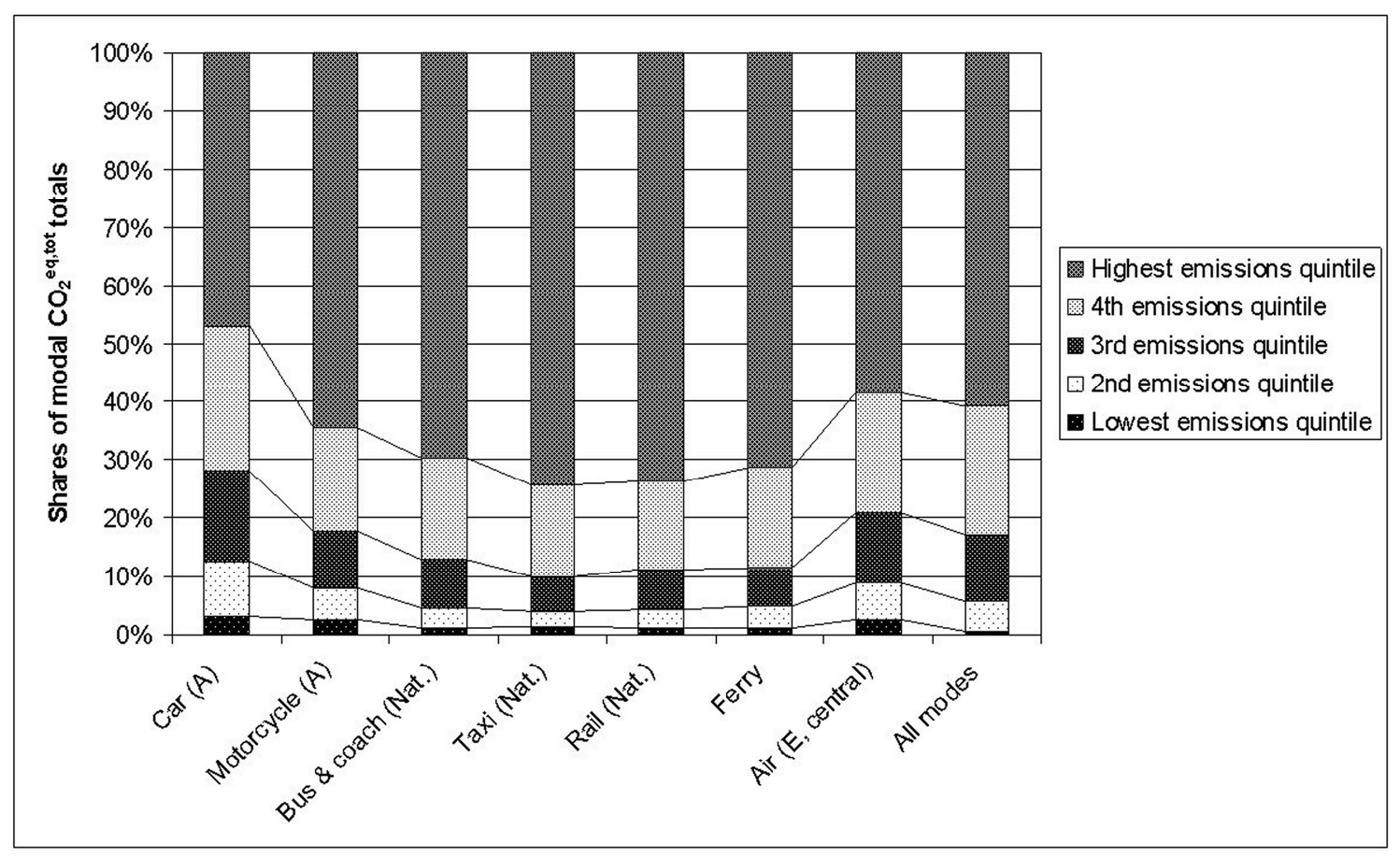

Bases: 266 (car), 12 (motorcycle), 313 (bus \& coach), 210 (taxi), 239 (rail), 68 (ferry), 269 (air)

Notes: Car - method A, air - method E and central AIM value, public transport - national average load factors and emissions rates

Similarly, the top emissions decile (10\%) of the sample are responsible for $43 \%$ and the bottom emissions decile of the respondents only $0.1 \%$ of the $\mathrm{CO}_{2}{ }^{\text {eq,tot }}$ resulting from all travel in this research. When compared to the sample as a whole, respondents in the top emissions decile were typically in their 30s and $40 \mathrm{~s}$, in full-time work or at university and earning £30k or more. Almost all of the respondents in the top emissions decile flew regularly, undertaking on average 12.7 LTOs and flying 53,861 km per year. In terms of total distance travelled, this is more than 5 times the sample average $(10,249 \mathrm{~km} \mathrm{p.a.})$ and, astoundingly, $30 \%$ more than the circumference of the earth. $72 \%$ of the respondents in the top emissions decile drove a car an average of 13,570 driver-km per year (or $37 \mathrm{~km}$ a day) - i.e. 2.4 times the UK national average of 5,582 $\mathrm{km}$ taken from ONS (2005). In contrast, respondents in the lowest impact decile were typically women, children (aged 6-17 years) or residents older than 75 years, not economically active residents, non-car drivers and residents on low income of less than £10k p.a. These revelations are significant for the realisation that intervention must be particularly aimed at a minority of the population in order to be effective. It is also key to the realistic setting of targets. Above all, it is the composition of 
both the specific travel related causes of these highest emissions levels and the people producing them that are important contributions to the literature to be gained from this work.

So who are the high and low emitters? Part of the answer is provided by segmenting the population according to demographic, socio-economic and other factors such as car availability. To assess the significance and degree of confidence of the analysis, chi-square tests were performed in order to find out whether or not there is a relationship between socio-economic characteristics (as defined by bands of income, age, gender, etc.) and emissions levels (as defined by income quintiles) and, if so, how strong the relationship is. The null hypothesis postulates there is no relationship of significance (at pre-set degrees of confidence of $1 \%, 5 \%$ and $10 \%$ ) while the alternative hypothesis postulates there is a relationship of significance. For each test, the total $\chi^{2}$, degrees of freedom, $\chi^{2}$ probability and critical $\chi^{2}$ of the actual and expected frequencies were calculated. As an example, Table 4 shows the results of the $x^{2}$ tests for the relationships between income groups and emissions quintiles ('highly significant' and 'significant' in bold).

Table 4: Chi-square test results for the relationships between emissions quintiles and income groups of all cases, by mode of transport (1)

\begin{tabular}{l|ccc|cc}
\hline Travel mode & Total $x^{2}$ & Degrees of freedom & $x^{2}$ probability ${ }^{(2)}$ & Cramer's phi & phi-square \\
\hline Car & $\mathbf{1 0 7 . 0}$ & $\mathbf{1 2}$ & $<0.001$ & 0.28 & $\mathbf{0 . 0 8}$ \\
Motorcycle & $\mathbf{3 1 . 2}$ & 4 & $<0.001$ & 0.26 & 0.07 \\
Bus \& coach & 26.2 & 16 & 0.051 & 0.12 & 0.01 \\
Taxi & 35.0 & 12 & $<0.001$ & 0.16 & 0.03 \\
Rail & 41.5 & 12 & $<0.001$ & 0.17 & 0.03 \\
Ferry & 9.6 & 4 & 0.048 & 0.15 & 0.02 \\
Air & 34.6 & 12 & 0.001 & 0.16 & 0.03 \\
\hline All travel & 110.5 & 16 & $<0.001$ & 0.25 & 0.06 \\
\hline
\end{tabular}

Notes: ${ }^{(1)}$ Significance tests based on the entire sample of 456 individuals, including travellers and non-travellers (drivers and non-drivers for car, flyers and non-flyers for air travel, etc.). (2) The relationship was defined as being 'highly significant' for $x 2$ probabilities of $1 \%$ or below, 'significant' for $x^{2}$ probabilities of between $1 \%$ and $5 \%$, 'modestly significant' for $X 2$ probabilities of between $5 \%$ and $10 \%$, and 'not significant' for $X 2$ probabilities of more than $10 \%$.

Overall, the uni- and multivariate analyses provide evidence on the connection between GHG emissions and:

- Income: in terms of GHG emissions from all travel, more than a quarter of the respondents in the highest emissions quintile were in the highest income group ( $>£ 40 \mathrm{k}$ per person p.a.), while about three-quarters of the respondents in the lowest emissions quintile were in the lowest income group $(<£ 10 \mathrm{k}$ per person p.a.). Respondents in the highest income group produced on average 3.5 times the annual emissions level of respondents in lowest income group. This disproportionality was 
significant (chi square test, $p<0.05$ ) for 'all travel', car, rail and taxi, while the link between air travel emissions and income was found to be relatively weak for the flyers (59\% of the sample population) but highly significant $(p<0.01)$ for the sample as a whole. The strong link between emissions and personal income is further examined in Figure 4, showing the modal breakdown of average GHG emissions per person in relation to personal income. The Figure further shows the relative contributions to $\mathrm{CO}_{2}$ equivalent $\left(\mathrm{CO}_{2}{ }^{\mathrm{eq}}\right)$ from $\mathrm{CO}_{2}$ and non- $\mathrm{CO}_{2}\left(\mathrm{CH}_{4}, \mathrm{~N}_{2} \mathrm{O}\right)$ emissions. While this again highlights the importance of non- $\mathrm{CO}_{2}$ emissions from air travel, only non-CO2 emissions from car travel have any significance overall.

Figure 4: Modal breakdown of average greenhouse gas emissions per person by income group, disaggregated by $\mathrm{CO}_{2}$ and non- $\mathrm{CO}_{2}$ emissions

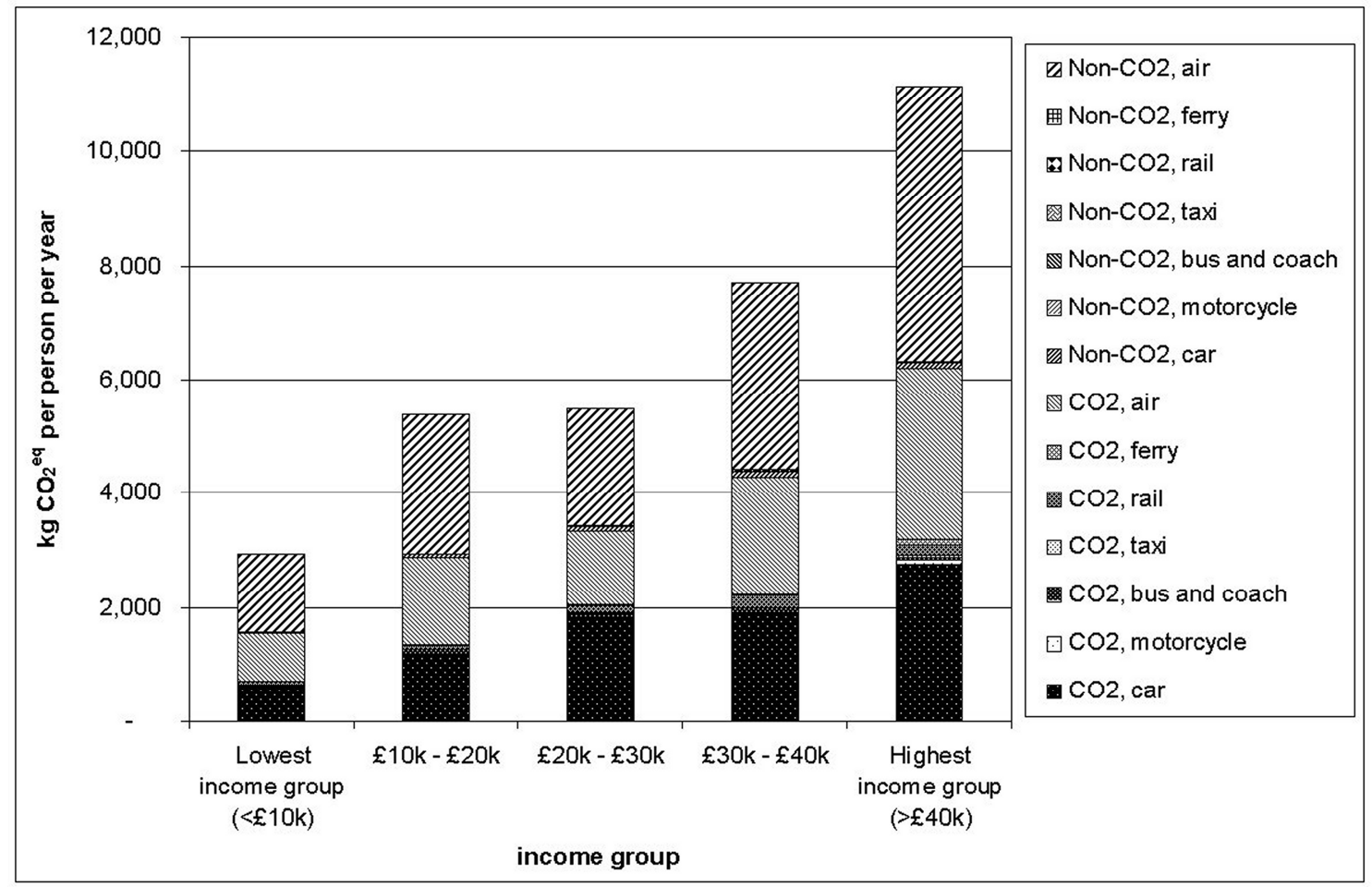

\section{Base: all 456 respondents}

Notes: 1. The number of cases/respondents in each income group is not necessarily equal. The groups do not present income quintiles. 2. Car - method A, air - method $E$ and central AIM value of 3, public transport - national average load factors and emissions rates

- Economic activity: about three-quarters of those in the top emission quintile were in work, whilst about four-fifths of those in the lowest emissions quintile were not. The relationship was highly significant $(p<0.01)$ for emissions from 'all travel', car and rail. Emissions from rail travel provide the strongest of these links, likely to be rooted in good accessibility to rail services for many respondents and the relatively high share of regular rail users (commuters). As with income, air travel 
emissions showed only weak links to working status of the flyers but a highly significant disproportionality with all respondents;

- Gender and travel by private vehicles: for car travel, two-thirds of respondents in the highest emissions quintile were male, while equally two-thirds of respondents in the lowest emissions quintile were female. The men in the highest car emissions quintile were predominantly in full-time employment, aged between 36 to 65 years, with income of $£ 20 \mathrm{k}$ or more and living in households with higher than average car availability. Motorcycle travel was $100 \%$ dominated by men. Interestingly, the link between gender and GHG emissions was not significant for any other mode of travel;

- Gender, other socio-economic factors and emissions from all travel: multivariate analysis showed gender and working status had a highly significant influence $(p<0.01)$ on emissions levels from 'all travel' and car travel. Also, a quarter of respondents in the lowest emissions quintile were women in retirement age, while equally a third of respondents in the highest emissions quintile were men between 36 and 65 years of age (Figure 5);

Figure 5: Composition of survey responses by gender and age, ranked by emissions quintile (all travel)

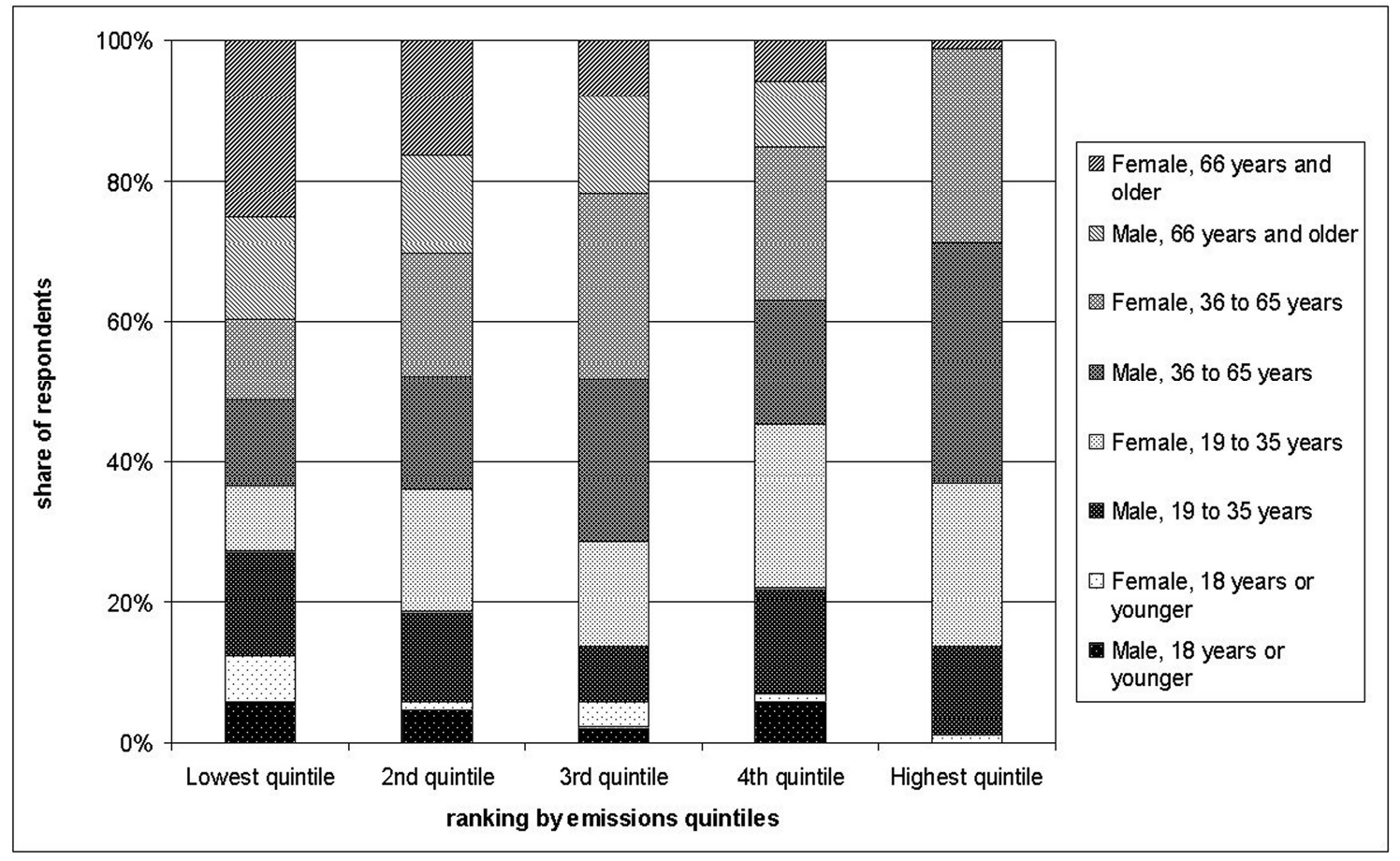

Base: 434 respondents with non-zero emissions and who provided information about gender and age

- Age: even though the 36-65 year olds comprised only about two-fifths of the respondents, they were responsible for more than half of the total GHG emissions and producing on average 3.6 and 2.6 
times the annual emissions level of the respondents in retirement age ( $>65$ years) and children (18 years or younger) respectively. Two-thirds of respondents in the highest emissions quintile (all travel) were between 36 and 65 year old, while two-fifths of respondents in the lowest emissions quintile were 66 years or older. The association between age and emissions levels was highly significant $(p<0.01)$ for 'all travel', car, rail and, crucially, air travel. It was also significant $(p<0.05)$ for travel by bus \& coach;

- Household composition and size: overall, individual averages compared well with published sources (e.g. ONS, 2004). Single person households showed the highest average emissions levels per individual (16\% higher than the sample-household average), mainly because of higher than average emissions from air travel. Households with three individuals showed the lowest average emissions level per person, yet the highest contribution from car travel, which was concluded to be due to differences in household composition (presence of children) and associated car use. While households with children are associated with higher distances travelled per driver than households without children (e.g. Best and Lanzendorf, 2005), this is outweighed by the increase in children;

- Car availability, which showed strong relationship with emissions. Overall, households with access to two cars or more produced about $75 \%$ higher emissions levels per household than the sample average and more than twice the figure for households owning only one car. Similarly, emissions from car travel alone were highest from households with access to two cars or more at about twice the sample average;

- Car ownership (company car vs. private car): for personal usage, company cars were driven about $50 \%$ further than private cars, with even higher distances travelled on business in company cars. As found in other research (e.g. Hughes, 1994, ONS, 2005), the company cars in this sample were significantly younger and larger (in terms of engine size) than the average car fleet.

\section{Discussion}

Cross-modal, socio-economic group and location-specific emissions data for individuals and households seldom exist together. The methodology and tool tested here is an example of the type of adaptable, multi-output yet potentially policy-specific method which needs to be developed further and employed nationally if the measurement and influencing of travel activity and associated GHG emissions are to become a serious and effective component of policy development and assessment. The results have highlighted implications for policy and strategy development, which are discussed next. 


\section{Insights for policy}

The differences that exist between the general population and subgroups within the population have farreaching consequences for the development of transport, energy and environmental policies. Indicators of travel and emissions were identified, such as those characteristics indicative of higher income, being in work, being female in pensionable age, middle age, small household size, higher car availability and the presence of a company car.

Climate change mitigation policy should focus primarily on air and car travel. Particular attention should be paid to air which, when non- $\mathrm{CO}_{2}$ climate effects are included via a multiplier, can account for $56 \%$ (low), 70\% (central) or 76\% (high) of passenger transport GHG emissions at the individual level.

Overall, household location influences GHG emissions production, with significantly higher than average emissions from car travel in rural areas and higher than average emissions from air travel in urban areas. However, when accounting for socio-economic and other factors, the evidence derived in the statistical and regression analyses (reported elsewhere e.g. Brand, 2006) suggests that location does not influence travel activity and GHG emissions significantly. This result contributes to the literature on the linkages between travel activity, emissions generation and their underlying influences (e.g. Carlsson-Kanyama and Linden, 1999, Timmermans et al., 2003, Cameron et al., 2004). Residents in large urban areas may experience more difficulties in meeting any future caps on personal GHG emissions (e.g. as part of carbon cap-and-trading) - yet alternatives to the car are generally available, so the scale of any equity impacts will be lower. However, regular flying will most certainly pose a challenge to meeting carbon caps. The respondents in the top emissions decile produced $19.1 \mathrm{tCO}_{2}{ }^{\text {eq,tot }}$ per person per year (central $A I M$ value) from flying alone. This has important implications for any future Personal Carbon Allowance (PCA) scheme, where allowances would be reduced year on year to a 'safe' level in terms of avoiding disastrous climate change. This 'safe' level is estimated to be around 3-4 $\mathrm{tCO}_{2}{ }^{\text {eq,tot }}$ per capita p.a. in 2050 (Meinshausen, 2006). Thus the top 10\% emitters of the population may use up their future annual carbon allowance in a couple of months unless they flew less or bought carbon allowances at prices that are expected to increase considerably by 2050 , especially if the UK Government decided to (artificially) align price with the expected increase in the social cost of carbon (Watkiss et al., 2005) by limiting carbon supply. 
Broadly based on, and positioned at opposite ends of, the environmentalist's view of the world (O'Riordan, 1976), carbon pricing (technocentric) and cap-and-trading (ecocentric) of carbon emissions are two of the main policies to tackle $\mathrm{CO}_{2}$ emissions and believed to have great potential to meet reduction targets cost-effectively. Following the 2006 UK Energy Review, PCAs are currently being investigated by the UK government to combat rising domestic emissions (DEFRA, 2006b). The debate continues as to what approach to use, and who to include. For instance, as people in practice have limited manoeuvring space regarding where they can afford to live, this in turn will affect the feasibility of PCA based policy instruments for transport.

A further key issue relates to the passenger aviation sector, which is currently largely excluded from both fuel taxation and emissions trading, suggesting something must be done sooner rather than later to curb the faster-than-GDP rate increases in demand and its effects on climate change. The link between income levels and emissions further confirms other research (Brons et al., 2002; Cairns and Newson, 2006) suggesting that prices would have to go up considerably to have a restraining effect on demand (from the high emitters, i.e. higher income groups), mainly because of the inelasticity of air travel demand.

Finally, as the 'hockey stick' shaped emissions-ranking curve is surprisingly similar when compared between modes, location and unit of analysis, policy needs to target the gross polluters, i.e. certain subgroups of the population who are responsible for a disproportionally large share of total emissions. Policy has to seek out these differences, identify the causes and target these causes directly. The following section briefly explores some of the main issues and potential uses of the research presented here.

\section{Potential uses of the methodology and evaluation tool}

The methodology and tool could potentially be used for developing policy and strategies and assessing the likely effects of these in impact and longitudinal studies. An important application would be to assess the climate change and emissions impacts of interventions aimed at changing people's travel behaviour (Cairns et al., 2004, Anable et al., 2005). In addition, the methodology could potentially be employed in awareness raising, informing, advising and giving feedback on travel activity and emissions at the household and individual levels. One option is to notify participants whether they fall into the highest or 
lowest emissions quintiles. An attempt has been made at designing a one-page Household GHG

Emissions Report, shown in Figure 6 for a five-person household drawn from the sample. The top half gives feedback on where the household falls in terms of GHG emissions quintiles of all five-person households in the UK. The bottom half gives more detail on individual travel activity and emissions totals and modal contributions to these totals. It further provides some 'expert advice' and 'personalised suggestions' on how to reduce emissions in the future. 
Figure 6: Prototype 'Household GHG Emissions Report' for feedback and advice

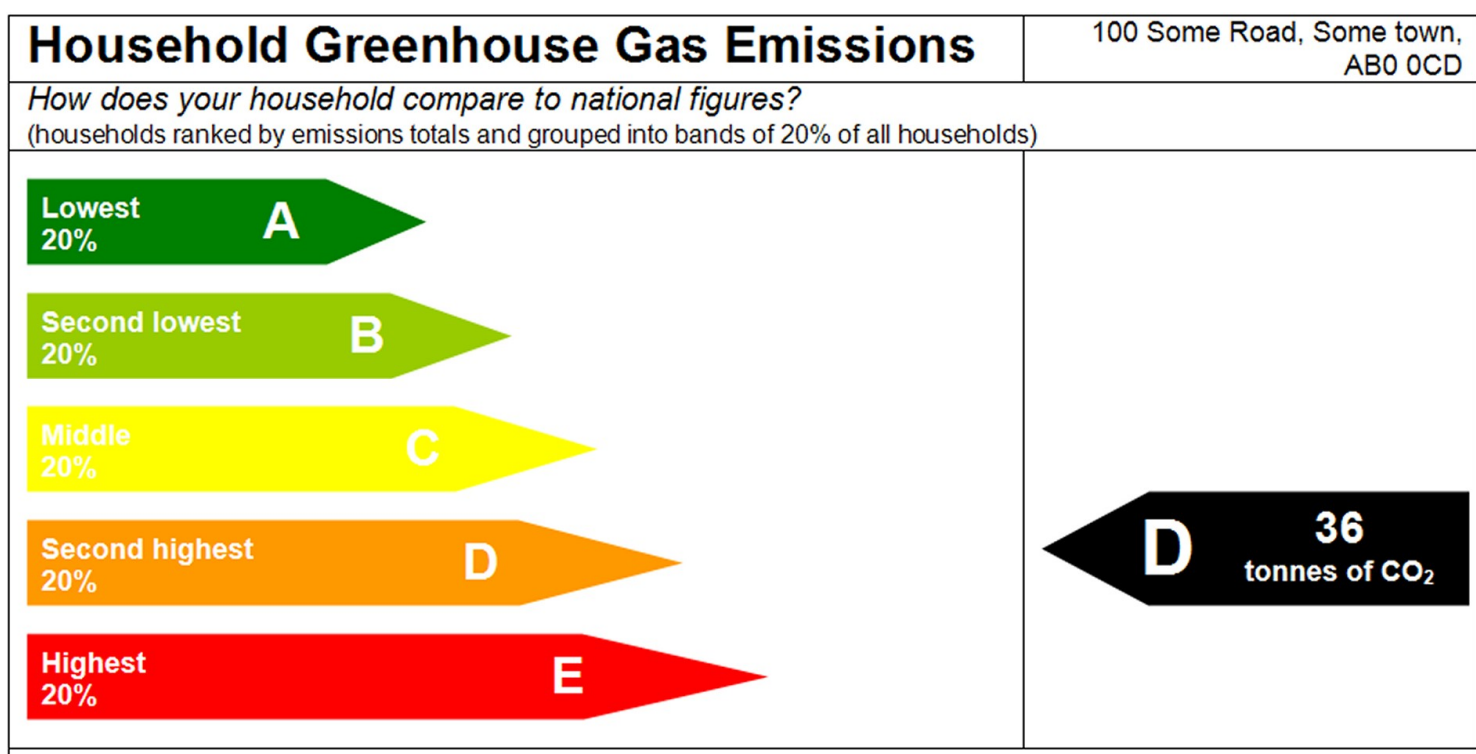

Your travel and associated emissions

- At nearly 74,000 miles, your household travels $86 \%$ more than the average 5 -person household

- The one return flight to Los Angeles dominates total miles travelled by all members of your household

- Car travel comes second overall, however with $25 \%$ less than the 5-person household average.

- Rail miles are $60 \%$ more than the 5-person household average. Bus miles are slightly less than average

- You walk and cycle considerably more than the national average, with major health benefits

- Your household greenhouse gas emissions are $61 \%$ higher than the 5-person household average

- You fall into the second highest emissions quintile of all UK households

- The long-haul flight to LA is the main culprit

- At the individual level, Stephen is the highest emitter, mainly because of the highest car travel emissions (nearly $50 \%$ higher than national average per person)

- Emissions from public transport play no major role

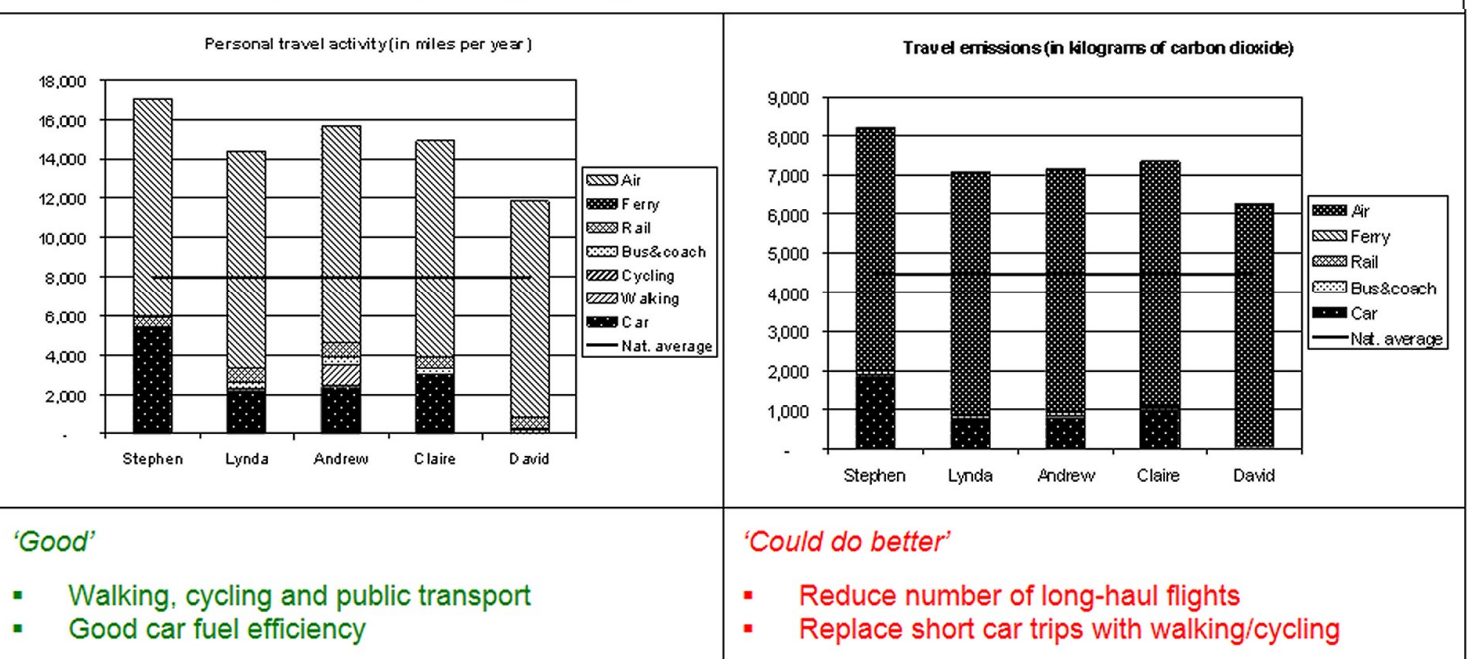

Expert advice

- Think of spending next year's holiday in the UK or Europe (preferably by rail)

- Walk and cycle even more for short journeys, thus reducing car use, with potentially major health benefits in the long run.

- Next time you buy a car, get an even more efficient one, e.g. a hybrid electric. Your two diesel cars boast better than average fuel economy and carbon dioxide emissions performance. One of the cars is getting a bit old. Thus there is an opportunity to either get rid of it without replacement or buy a fuel efficient, low carbon car instead. The fuel economy label shown on new cars in the showrooms and the car fuel and emissions data (www.vcacarfueldata.org.uk) can give advice on what car is best. 
The potential for a predictive model of aggregate emissions and personal travel activity based on personal characteristics influencing emissions was investigated. Multiple regression analyses were performed in parallel work which is reported in Brand (2006) and Brand (forthcoming). Although not reported here, the results suggest there are significant relationships between outcomes (emissions, travel activity) and predictors (socio-economic and other factors, in particular income, economic activity, age, household size and car availability). However, the regression models explained only up to two-fifths of the variation in outcomes, and only a relatively small number of categorical independent variables were significant for each model. Thus, other factors such as attitudes, lifestyle and personal circumstances are likely to play an important role in explaining the other variations. This suggests that there is a need for an alternative or complimentary segmentation of the personal travel market, for example by segmenting the population into potential 'mode switchers' via cluster analysis as performed by Anable (2005).

The potential for a detailed 'household carbon end-use model' for household and transport energy use and GHG emissions was identified. Although this paper focuses solely on transport, broader based personal carbon emissions from household energy use and travel could be explored, instead of focusing on transport only. The size and quality of the home, the kind of heating, as well as food choices also greatly contribute to the overall attributable carbon budget of a household. Arguably, handling transport separately may risk hitting the households harder than necessary.

\section{Conclusions and outlook}

This research contributes to the literature primarily by providing an innovative assessment framework and evaluation tool for cross-modal travel emissions profiling at the personal and household levels, thus providing a more complete yet cost-effective assessment of travel emissions. It fills the knowledge gap of limited geographical and modal coverage of travel emissions profiles. It further contributes to the debate and search for an accepted methodology for auditing GHG emissions from all personal travel and the elaboration of PCA methods with special reference to transport. The research has produced a rich and extensive dataset providing an improved understanding of the overall extent and composition of GHG emissions from personal travel within a 12-month timeframe. This disaggregate dataset did not exist before. A number of important policy implications have been identified, including effectiveness and equity issues as well as issues of scale and practicality. The research further contributes to the growing body of transport research focussing on changing travel behaviour rather than relying on technology to fix 
the climate change problem. By providing insights into the demographic and socio-economic profile of travel emissions, this work gives clues to who is polluting the most and who is likely to be affected most by policy responses such as pricing and carbon cap-and-trading.

Areas for further research are briefly summarised here. First, the tool employed a number of alternative methods and calculation techniques, some of which have been found to be incomplete or too resourceconsuming. Further work could focus on the one or two methods that have proved to be most promising and accurate in providing emissions profiles at all levels of analysis. Secondly, in earlier research Banister (1993) concluded that settlement size together with the availability of local facilities, services and employment, are the key determinants of travel and energy consumption. This conclusion could be tested and scrutinised further by linking household location data and the Accession ${ }^{\odot}$ accessibility planning tool (MVA, 2006) already used by some Local Authorities (e.g. Oxfordshire County Council, 2005). Thirdly, as indicated above, the methodology could relatively easily be extended to all personal carbon emissions, thus integrating travel and domestic energy use. One interesting application of such a tool would be to accurately assess the 'before' and 'after' effects of home working amongst large scale employers on overall carbon emissions, extending previous work on tele-commuting and tele-working (e.g. Banister et al., 2007). Fourthly, the aggregate forecasting model could be developed further, for example for each mode and/or population group based on personal characteristics or, alternatively, attitudinal and lifestyle factors. The latter would require a change in survey design and content with the view to elicit attitudinal factors and willingness to change as suggested by Anable (2005). This could then be validated by repeating the surveys and running the model in a time series year on year. Finally, there is an opportunity to incorporate elements of the survey and emissions evaluation methods explored here into more established travel survey methods such as travel diaries. Travel emissions diaries would be able to assess and evaluate policy aimed at changing daily travel behaviour. Additional data would need to be collected on less regular, casual travel such as annual holidays, visiting family and friends. Other elements of this research may be incorporated, e.g. survey questions on private vehicle technology (make/model, fuel type, engine size, etc.), records of annual distance travelled and fuel use, and household income.

The taming of the few has barely begun. Let's get moving - low carbon style.

\section{References}

AEA (2002) Statistical Appendices to Yearbook 2002. Brussels, Association of European Airlines. 
ANABLE, J. (2005) 'Complacent Car Addicts' or 'Aspiring Environmentalists'? Identifying travel behaviour segments using attitude theory. Transport Policy, 12, 65-78.

ANABLE, J., BOARDMAN, B. \& ROOT, A. (1997) Travel Emissions Profiles: a tool for strategy development and driver advice. Oxford, Environmental Change Unit, University of Oxford.

ANABLE, J., KIRKBRIDE, A., SLOMAN, L., NEWSON, C., CAIRNS, S. \& GOODWIN, P. (2005) Soft measures - soft options or smart choice? 37th Conference of the Universities Transport Studies Group, 5-7 January. Bristol, Universities Transport Studies Group.

BANISTER, D. (1993) Energy use, transport and settlement patterns. IN BREHENY, M. (Ed.) Sustainable Development and Urban Form. London, Pion.

BANISTER, D. \& BANISTER, C. (1995) Energy consumption in transport in Great Britain: Macro level estimates. Transportation Research Part A: Policy and Practice, 29, 21-32.

BANISTER, D., NEWSON, C. \& LEDBURY, M. (2007) The Costs of Transport on the EnvironmentThe Role of Teleworking in Reducing Carbon Emissions, Final Report. Transport Study Unit, Oxford University Centre for the Environment, Oxford.

BARLOW, T. J., HICKMAN, A. J. \& BOULTER, P. (2001) Exhaust Emission Factors 2001: Database and Emission Factors, TRL Report PR/SE/230/00. Crowthorne, TRL.

BEST, H. \& LANZENDORF, M. (2005) Division of labour and gender differences in metropolitan car use: An empirical study in Cologne, Germany. Journal of Transport Geography, 13, 109-121.

BRAND, C. (2006) Personal Travel and Climate Change: exploring climate change emissions from personal travel activity of individuals and households, unpublished DPhil thesis. Oxford University Centre for the Environment. Oxford, Oxford University.

BRAND, C. (forthcoming) Counting Carbon: The development of integrated travel emissions profiles, submitted to Transport Policy.

BRISTOW, A., PRIDMORE, A., TIGHT, M., MAY, T., BERKHOUT, F. \& HARRIS, M. (2004) How Can We Reduce Carbon Emissions from Transport?, Technical Report 15 and final report from Tyndall research project IT1.7. Leeds, Tyndall Centre for Climate Change Research.

BRÖG, W., ERL, E. \& MENSE, N. (2004) Individualised Marketing: Changing Travel Behaviour for a better Environment. IN OECD (Ed.) Communicating Environmentally Sustainable Transport The Role of Soft Measures. Paris, OECD.

BRONS, M., PELS, E., NIJKAMP, P. \& RIETVELD, P. (2002) Price elasticities of demand for passenger air travel: a meta-analysis. Journal of Air Transport Management, 8, 165-175.

CAA (2006) January 2006 Airline Statistics. London, Civil Aviation Authority, TSO.

CAIRNS, S. \& NEWSON, C. (2006) Predict and decide: aviation, climate change and policy. Oxford, UKERC, Demand Reduction Theme.

CAIRNS, S., SLOMAN, L., NEWSON, C., ANABLE, J., KIRKBRIDE, A. \& GOODWIN, P. (2004) Smarter Choices - Changing the Way We Travel, Final report of the research project: The influence of soft factor interventions on travel demand. London, Department for Transport (DfT), TSO.

CAMERON, I., KENWORTHY, J. R. \& LYONS, T. J. (2003) Understanding and predicting private motorised urban mobility. Transportation Research Part D: Transport and Environment, 8, 267283.

CAMERON, I., LYONS, T. J. \& KENWORTHY, J. R. (2004) Trends in vehicle kilometres of travel in world cities, 1960-1990: underlying drivers and policy responses. Transport Policy, 11, 287-298.

CARLSSON-KANYAMA, A. \& LINDEN, A.-L. (1999) Travel patterns and environmental effects now and in the future: implications of differences in energy consumption among socio-economic groups. Ecological Economics, 30, 405-417.

CONCAWE (2006) Well-to-Wheels analysis of future automotive fuels and powertrains in the European context, version 2b of May 2006 (last accessed at http://ies.jrc.cec.eu.int/wtw.html on 19/07/06). Brussels, CONCAWE, EUCAR \& JRC/IES.

DEFRA (2006a) Climate Change: The UK Programme 2006. London, Department of the Environment, Food and Rural Affairs (DEFRA), TSO.

DEFRA (2006b) Government to look at personal carbon allowances to combat rising domestic emissions, News Release 19 July 2006 (last accessed at http://www.defra.gov.uk/news/2006/060719b.htm on 22/07/06). London, DEFRA. 
DfT (2005) Transport Statistics Great Britain 2005. London, Department for Transport (DfT), TSO.

DfT (2006) Climate change and transport. London, Department for Transport (DfT), TSO.

DLR (2000) Databases with emissions profiles of civil jets, drawn up by the German Aerospace Center (Deutsches Centrum fuer Luftraumfahrt). IN GEMAN FEDERAL ENVIRONMENTAL AGENCY, T.-R., DIW, WUPPERTAL INSTITUTE FOR ENVIRONMENT, CLIMATE AND ENERGY (Ed.) Maßnahmen zur verursacherbezogenen Schadstoffreduzierung des zivilen Flugverkehrs [Measures for polluter-related pollution reduction in civil aviation], research project 10506085 . Friedrichshafen, Deutsches Centrum fuer Luftraumfahrt.

DTI (2003) Energy White Paper: Our energy future - creating a low carbon economy. London, Department of Trade and Industry (DTI), TSO.

ECI (2006) Climate Change: DEFRA Committee to examine the "citizen's agenda", Response to consultation from the Environmental Change Institute, University of Oxford. Oxford, Environmental Change Institute, University of Oxford.

EEA (2005) Air Traffic: Activities 080501 - 080504. IN EEA (Ed.) EMEP/CORINAIR Emission Inventory Guidebook, 4th Edition, Technical report No 30. Copenhagen, European Environment Agency.

FOX, M. (1995) Transport planning and the human activity approach. Journal of Transport Geography, 3, 105-116.

GREENING, L. A. (2004) Effects of human behaviour on aggregate carbon intensity of personal transportation: comparison of 10 OECD countries for the period 1970-1993. Energy Economics, 26, 1-30.

GREENING, L. A., SCHIPPER, L., DAVIS, R. E. \& BELL, S. R. (1997) Prediction of Household Levels of Greenhouse-Gas Emissions from Personal Automotive Transportation. Energy, 22, 449-460.

HICKMAN, R. \& BANISTER, D. (2006) Looking over the horizon - Visioning and Backcasting for UK Transport Policy (VIBAT), Final Report. London, Halcrow Group Ltd. and University College London for the Department for Transport.

HILLMAN, M. \& FAWCETT, T. (2004) How We Can Save the Planet, London, Penguin.

HILLMAN, M. \& WALLEY, A. (1983) Energy and personal travel: obstacles to conservation. London, Policy Studies Institute.

HOUGHTON, J. T., DING, Y., GRIGGS, D. J., NOGUER, M., VAN DER LINDEN, P. J. \& XIAOSU, D. (2001) Climate Change 2001: The Scientific Basis, Part of the Working Group 1 Contribution to the Third Assessment Report of the International Panel on Climate Change, Cambridge, International Panel on Climate Change (IPCC), Cambridge University Press.

HUGHES, P. (1994) Personal Transport and the Greenhouse Effect, London, Earthscan Publications Ltd.

IPPR (2003) Putting the brakes on climate change: a policy report on road transport and climate change. London, Institute for Public Policy Research (IPPR).

KORBETIS, M., REAY, D. S. \& GRACE, J. (2006) New Directions: Rich in $\mathrm{CO}_{2}$. Atmospheric Environment, 40, 3219-3220.

MEINSHAUSEN, M. (2006) $<2^{\circ} \mathrm{C}$ Trajectories - a Brief Background Note, KyotoPlus - Papers. Potsdam, Potsdam Institute for Climate Impact Research (PIK), Germany.

MVA (2006) ACCESSION, Version 1.5. Woking, Citilabs and MVA.

NETCEN (2003) National Atmospheric Emissions Inventory (NAEI). Harwell, NETCEN for the Department for the Environment, Food and Rural Affairs.

NILSSON, M. \& KULLER, R. (2000) Travel behaviour and environmental concern. Transportation Research Part D: Transport and Environment, 5, 211-234.

O'RIORDAN, T. (1976) Environmentalism, London, Pion.

ONS (2001) Census. London, Office of National Statistics.

ONS (2004) The impact of UK households on the environment through direct and indirect generation of greenhouse gases. London, Office for National Statistics (ONS).

ONS (2005) Transport Statistics Bulletin: National Travel Survey 2004. London, Office of National Statistics, Transport Statistics: Department for Transport.

OXFORDSHIRE COUNTY COUNCIL (2000) Oxford Transport Strategy: Assessment of Impact.

Oxford, Oxfordshire County Council. 
OXFORDSHIRE COUNTY COUNCIL (2005) Framework Accessibility Strategy, Provisional Local Transport Plan 2006-2011. Oxford, Oxfordshire County Council.

PENNER, J. E., LISTER, D. H., GRIGGS, D. J., DOKKEN, D. J. \& MCFARLAND, M. (1999) Aviation and the Global Atmosphere. Geneva, Intergovernmental Panel on Climate Change (IPCC).

SAUSEN, R. (2005) Aviation radiative forcing in 2000: An update on the IPCC (1999). Meteorologische Zeitschrift, 14, 555-561.

SHINE, K. P., BERNSTEN, T. K., FUGLESTVEDT, J. S. \& SAUSEN, R. (2005) Scientific issues in the design of metrics for inclusion of NOX in global climate agreements. Proceedings of the National Academy of Sciences, 102, 768-773.

STEAD, D. (1999) Relationships between Transport Emissions and Travel Patterns in Britain. Transport Policy, 6, 247-258.

THE PEDESTRIANS ASSOCIATION (2001) Streets are for Living: The Importance of Streets and Public Spaces for Community Life. (Last accessed online www.livingstreets.org.uk/Full\%20report.pdf on 20-03-2004.). London, The Pedestrians Association.

TIMMERMANS, H., VAN DER WAERDEN, P., ALVES, M., POLAK, J., ELLIS, S., HARVEY, A. S., KUROSE, S. \& ZANDEE, R. (2003) Spatial context and the complexity of daily travel patterns: an international comparison. Journal of Transport Geography, 11, 37-46.

UNCED (1992) Rio Declaration on Environment and Development, last accessed at http://www.unep.org/Documents/Default.asp?DocumentID=78\&ArticleID=1163 on 20/08/05. Rio de Janeiro, UNCED.

WATKISS, P., ANTHOFF, D., DOWNING, T., HEPBURN, C., HOPE, C., HUNT, A. \& TOL, R. (2005) The Social Cost of Carbon, The Social Costs of Carbon (SCC) Review - Methodological Approaches for Using SCC Estimates in Policy Assessment, Final Report. London, AEA Technology for DEFRA.

WIT, R. C. N., BOON, B. H., VAN VELZEN, A., CAMES, M., DEUBER, O. \& LEE, D. (2005) Giving wings to emission trading: Inclusion of aviation under the European emission trading system (ETS): design and impacts. Delft, CE Delft for the European Commission, DG ENV. 